\title{
Aproximación a la historia del “imperialismo editorial" de Estados Unidos en la etapa preindependentista cubana: entre la necesidad y el exilio
}

\author{
Juan José Sánchez Baena \\ Universidad de Murcia
}

\begin{abstract}
Análisis bibliográfico externo e interno de los fondos impresos del siglo XIX publicados en Estados Unidos, pertenecientes a dos importantes bibliotecas cubanas, la de la Oficina del Historiador, formada por colecciones privadas, y la de la Sociedad Económica de Amigos del País, de acceso público.

El exilio cubano en Estados Unidos formó en Nueva York el núcleo impresor más importante. Sus imprentas avanzaban al ritmo de los movimientos socio-políticos de anexionistas e independentistas. Los formatos más utilizados para la batalla ideológica librada desde el exterior eran, aparte de las publicaciones periódicas, el folleto y el cuaderno.

Los resultados confirman que para las obras permitidas, el encorsetamiento editorial producido por la censura no podía cubrir las necesidades de obras impresas del público cubano, lo que unido al desarrollo de las imprentas norteamericanas y al momento de expansión del país vecino, hicieron posible la creación en Cuba de un mercado para las obras impresas en Estados Unidos.
\end{abstract}

\section{Introducción}

A pesar de que el establecimiento de la imprenta en los territorios de la América anglosajona fue un siglo después que en Hispanoamérica, ${ }^{1}$ este retraso no fue determinante en el desarrollo de la misma. Por el contrario, el movimiento impresor y editorial norteamericano alcanzó un avance importante en poco tiempo y, además, sus obras lograron una amplia difusión interna y externa. El primer ejemplo documentado de ello lo encontramos en 1811, cuando llega al puerto de La Habana el bergantín "Boston" con un cargamento de libros que habían sido encargados por la Junta de Instrucciones al vecino país, cuya temática era mayoritariamente de economía y política norteamericana. ${ }^{2}$

1 Recordar que la primera imprenta en la América española data de 1539 en México, mientras que en Norteamérica la prensa más antigua comenzó a funcionar en Cambridge (Massachusetts) en 1638 .

2 Entre otros, los libros eran tres tomos de Hamilton's works, uno de Jefferson's notes, dos tomos de la famosa Humboldt's New Spain y tres de la American Review. Archivo Nacional de Cuba (ANC), Real Consulado y Junta de Fomento, 22, exp. 1295. Habana, 1811. 
En tan sólo cuarenta o cincuenta años de vida desde su independencia, Estados Unidos logró desarrollar y potenciar todo el espectro del "arte de imprimir" en casi todas sus vertientes. La continuación del camino iniciado por la metrópoli, y lo más importante, el mantenimiento y desarrollo de todos aquellos avances técnicos, materiales y de organización del trabajo, hace que los Estados Unidos, en muy poco tiempo, comiencen incluso a perfeccionar muchos de estos avances de la era industrial.

Obviamente, la imprenta también va a recoger parte de esa eclosión técnica, aplicándosele a todo lo que rodea al mundo de la impresión. Ya desde los comienzos, los jóvenes Estados Unidos fueron conscientes de la importancia de la divulgación de las ideas — políticas, culturales, económicas, etc.—, y por consiguiente, que la herramienta básica de difusión de la información, la imprenta, podía ser determinante en el desarrollo, consolidación y expansión del país. Así, no es de extrañar que en la primera mitad del siglo XIX ya hubieran adquirido, desarrollado, e incluso perfeccionado, la maquinaria más sobresaliente que en esos momentos había en el mundo. ${ }^{3}$ De esta manera, a fines de siglo la prensa se empezará a consolidar como uno de los poderes fácticos más importantes del país. ${ }^{4}$

Desde finales del siglo XVIII Estados Unidos mantenía una estrecha relación comercial con Cuba, ${ }^{5}$ convirtiéndose en uno de los impulsores más importantes del crecimiento económico de la Isla, sobre todo desde el comienzo del "boom" azucarero, ${ }^{6}$ determinante en el devenir histórico de la Isla. Y será en los años cuarenta del siglo XIX, coincidiendo además con dos de los temas más polémicos del momento, esclavismo y anexionismo, cuando asistamos a un aumento en la adquisición e introducción de obras impresas que llegaron del vecino país. ${ }^{7}$

3 Algunos ejemplos son: la "componedora" del norteamericano Willian Church construida en 1822, considerada la primera máquina automática de composición de textos. En 1845 Richard Hoe obtuvo en los Estados Unidos una patente a la primera rotativa moderna. En 1863 Willian A. Bullock obtiene otra patente referida a la primera rotativa para la impresión de libros sobre papel continuo. En 1866 el americano Tilghman ideó en la producción del papel el procedimiento al bisulfito. En 1884 el alemán Ottmar Mergenthaler inventa en la ciudad de Cincinnati la composición automática de textos, la linotipia ("line on type"). Otro aparato de uso muy extendido es la "monotipia" o "monotipo", inventado por el norteamericano Tolbert Lanston, cuyas primeras investigaciones se remontan a 1883 .

4 Dos buenas biografías en donde se estudian los cambios en la prensa en este sentido son: Swanberg, W.A.: Citizen Hearst. New York, 1961 y Juergens, G.: Joseph Pulitzer and the New York "World". New York, 1965.

5 Tornero Tinajero, P.: "Los Estados Unidos en la economía cubana del siglo XVIII". La América Española en la Epoca de las Luces. Madrid, 1988, págs. 201-218.

6 Moreno Fraginals, M.: El Ingenio. La Habana, 1978, 3 t.

7 Entre los años 1844 a 1848 asistimos a una expansión en la introducción de libros y periódicos estadounidenses que llegaban a distintos puntos de la Isla. ANC, Gobierno Superior Civil, 659, exp. 20769. Habana, 1844-1848. 
No sólo va a ser en los avances en el campo de la industria y las comunicaciones donde Estados Unidos verá en Cuba un buen negocio. ${ }^{8}$ También, desde muy temprano, la Isla representó un mercado de venta de su propia maquinaria y técnica en el contexto de la imprenta. Sirva de ejemplo la nota aparecida en el diario El Noticioso y Lucero de La Habana del año 1834 donde podía leerse:

“... hemos hecho venir de los Estados Unidos una ingeniosa prensa mecánica, la primera que se ha visto en este país, que tira 1.500 ejemplares por hora y cuyos primeros ensayos nos han dejado satisfechos". ${ }^{9}$

Este ejemplo no fue un hecho aislado, ya que se iba a desarrollar el concepto de competencia a raíz de estos nuevos avances. Así, en 1836 la imprenta de José Severino Boloña ${ }^{10}$ ofrece al público su nuevo catálogo de tipos y viñetas, presentándolo como la adquisición de lo último inventado en este campo:

“... gran acopio de caracteres y viñetas, cual no se había visto hasta el día en esta ciudad, y cinco prensas de patente de primer orden, con todos sus utensilios, principalmente una de ellas de un tamaño extraordinario, de máquina de nueva invención, en la que un niño puede trabajar con la mayor facilidad y prontitud; dos prensas de cortar impresiones y otras de marca mayor para aprensarlas, hecho venir todo con especial encargo de España, Francia y los Estados Unidos de América" ."

Esta situación originó que algunas de las imprentas importantes buscaran actualizar su maquinaria, siendo la mayoría de las veces sus suministradores los Estados Unidos, ya que la metrópoli no podía competir, ni en técnica ni en costos, con éstos.

La Isla se convierte así en un mercado para los editores e impresores establecidos en los Estados Unidos. Inversamente, éstos son a la vez para Cuba los suministradores de maquinaria de impresión, de formación especializada (muchos impresores o allegados a ellos, iban a formarse princi-

8 Algunos ejemplos significativos los encontramos en la primera mitad del siglo. Una de las mayores fábricas de maquinaria, la "Novelty Iron Works", y la "West Point Foundry" se especializaron muy pronto en maquinaria azucarera, desplazando y haciéndose con el mercado cubano en poco tiempo. Ambas se localizaban en Nueva York. Con la instalación del tramo de ferrocarril Habana-Bejucal la empresa norteamericana "Baldwin Locomotive Works" exportó las dos primeras máquinas construidas en Estados Unidos fuera de sus fronteras. Moreno Fraginals: El Ingenio, t. II, págs. 153 y 155.

9 Biblioteca Nacional José Martí (BNJM), Colección Cubana. Publicaciones periódicas.: "El Noticioso y Lucero de La Habana", viernes, 10 de octubre de 1834, pág. 2.

10 Sánchez Baena, J.J.: El libro en Cuba: Imprenta, bibliotecas y publicaciones periódicas, S. XVIII y XIX. Murcia, 1994, pág. 161.

11 Diego, E.: Muestrario del mundo o Libro de las maravillas de Boloña. La Habana, 1968, pág. 7 y ss. 
palmente en Nueva York, o Filadelfia), ${ }^{12}$ y sus imprentas, en centro de acogida para la difusión de ideas y de todos aquellos temas censurados por el gobierno español. Precisamente en el período que entramos a examinar, el término "editor" es aplicado a quien ejerce la industria de la producción y divulgación de obras por medio de la imprenta, aunque no siempre se ocupe del arte tipográfico y del comercio de libros.

La evolución económica y técnica de la imprenta norteamericana a fines de siglo XIX coincide con el desarrollo de acontecimientos importantes en Cuba. El propio José Martí, en un artículo de 1883 describía el fascinante mundo de la impresión en los Estados Unidos:

“¿Qué lujo de máquinas, estos obreros de hierro! ¡Qué minuciosos y artísticos cuidados del formador, del preparador, del prensista, del obrero hombre, máquina por ninguna otra vencida!". ${ }^{3}$

También manifiesta las virtudes de la obras allí publicadas:

“¿Qué nítidos, qué hermosos, qué convidadores son los libros que se imprimen en los Estados Unidos ${ }_{i} .$. no dan las prensas de país alguno tanto libro sólido, claro y perfecto. La obrilla más ruin, el más vano catálogo, el folleto veloz y levantisco que hoy hiere y mañana ya es perdido y pisoteado en el ardor de la batalla, están impresos de manera que invitan a escribir, por ver en molde tan gallardo los propios pensamientos, que parece que ya han de ser tenidos como buenos". ${ }^{14}$

Vamos pues a centrarnos en lo que supone el mundo de la edición e impresión en tierras norteamericanas en un aspecto concreto: su repercusión y relación directa o indirecta con los acontecimientos acaecidos en la isla de Cuba.

De las imprentas aquí citadas debemos distinguir, por un lado, aquellas cuyos titulares eran emigrantes cubanos, y por otro, las que tenían responsables o propietarios norteamericanos. Ambas suministraban aquellas publicaciones que la censura no dejaba producir en la isla, a las que llamaremos no oficiales, y una parte importante de las que estaban permitidas y que respondían a la demanda que en esos momentos generaba el mercado editorial de la Isla.

12 Un ejemplo lo tenemos en uno de los impresores y tipógrafos más importantes del siglo XIX en Cuba, Francisco Murtra, a quien su padre había enviado a Filadelfia, a la imprenta de James Hardig, para que aumentara y perfeccionara los conocimientos en el arte y la técnica de la impresión. Sánchez Baena: El Libro en Cuba: ..., pág. 141. Esta formación sería importante en la publicación de su Diccionario de tipografía cubana redactado, tal y como consta en el mismo, "para auxilio de los regentes, de los operarios cajistas, prensistas y demás que ejercen en esta Isla el noble arte de la imprenta". BNJM, Colección Cubana. Habana, 1859.

13 Martí Perez, J.: "Martí en los Estados Unidos. Plática de libros. Cómo se imprime un libro en los Estados Unidos”. En: Obras completas. La Habana, 1964, t. 13, pág. 420. Este artículo fue publicado en la revista La América de Nueva York en noviembre de 1883.

14 Ibídem, pág. 419. 


\section{Censura y exilio editorial}

La importancia del desarrollo de la imprenta en la historia de la formación de un país es evidente desde el momento en que ésta facilita la difusión de las nuevas ideas. El hecho de que se eligiera desde el comienzo ${ }^{15}$ Estados Unidos como centro neurálgico de operaciones responde a factores geográficos, políticos y económicos conocidos.

En la historia de Cuba hay abundantes muestras del temor que existía por parte del gobierno español de que tanto impresores como impresos se desviaran de la línea oficial marcada por la metrópoli. ${ }^{16}$ Ejemplos de esta política represora y de la importancia de la impresión en los procesos revolucionarios son las pequeñas imprentas portátiles ${ }^{17}$ que el ejército independentista llevaba entre sus armas, o los tipógrafos que pagaron con su vida el apoyo a conspiraciones contra el poder español en Cuba. ${ }^{18}$

Esta censura ejercida durante todo el período colonial en el ámbito de la impresión, fue la causa principal de la búsqueda de un lugar seguro fuera de Cuba, dando lugar a la dispersión editorial, y provocando dentro de la Isla el encorsetamiento de toda su producción literaria. Pero la censura no afectaba solamente a las publicaciones cubanas, sino que se extendía, tal y como hemos señalado anteriormente, ${ }^{19}$ a cualquier publicación que llegara a la Isla y que pusiera en duda las directrices de la política española:

“...y por lo mismo sería un bien la prohibición absoluta, no solo ahora sino en cualquier tiempo, de que entrasen en la isla los periódicos que ataquen el poder que exista en España". ${ }^{20}$

También eran continuas las disposiciones para impedir la importación de libros, folletos y "papeles de mala doctrina". ${ }^{21}$ Asimismo, en las leyes de

15 Ya desde los primeros años del siglo XIX las imprentas de los Estados Unidos se convirtieron, junto a los primeros emigrados independentistas en un "peligro" para la Isla. Un ejemplo de ello es la real orden para que no se permita la introducción en la ciudad de La Habana de "El Habanero", periódico que se publicaba en Filadelfia, bajo la dirección del presbítero Félix Varela. ANC, Asuntos políticos, 28, exp. 19. Habana, 1824.

16 Sánchez Baena, y Chaín Navarro, C.: "Prensa e Ilustración. Las élites cubanas y el control de la información a finales del siglo XVIII". En: Familia, tradición y grupos sociales en América Latina. Murcia, 1994, págs. 157-177.

17 Sánchez Baena: El libro en Cuba:..., págs. 179-180.

18 En esa relación independencia-imprenta podemos situar, por ejemplo, la conspiración fallida llamada de "Vuelta Abajo", que le costó la vida al tipógrafo Eduardo Facciolo. Ceballos, G.: Apuntes biográficos sobre Eduardo Facciolo y síntesis del proceso que culminó en su inmolación. La Habana, 1941.

19 Véase nota 15

20 Archivo Histórico Nacional (AHN), Ultramar, 8, exp. 24. Habana, 1845.

21 ANC, Cuba. Gobierno Superior Civil, 655, exp. 20568. Habana, 1841. 
imprenta con que se dotaba a la Isla siempre había algún artículo dedicado a la censura aplicable a las publicaciones que procedían del extranjero. Por ejemplo, el artículo 91 de la Ley de imprenta para la Isla de Cuba de 1881 otorgaba autorización al gobernador general "para prohibir la introducción y circulación en la Isla de Cuba de cualquier impreso de los que son objeto esta Ley". ${ }^{22}$ La posterior de 1886 y siguientes, mantendrá el espíritu de ésta. En las Memorias de la Sociedad Económica de Amigos del País de La Habana, se recoge el sentir general sobre este tema:

"En la época a que nos referimos el periodismo se encontraba consagrado a la literatura y a la crítica, puesto que la política estaba sujeta al capricho de un censor nombrado por el Gobierno, quien era a la vez fiscal de las obras que se introducían de la península y del extrangero ( $\mathrm{sic}$ ), a fin de evitar la lectura de libros políticos, sociológicos. Pero, a pesar de las prevenciones dictadas por las autoridades tanto civil como eclesiástica, se introducían obras sociales que eran leídas con avidez por el pueblo". ${ }^{23}$

Esta censura, además, contribuyó igualmente a reducir el interés de los autores por publicar sus obras en la Isla ya que al propio coste de las impresiones había que unir la fianza — sobre todo si de una nueva publicación periódica se trataba - y el seguimiento a veces agobiante de los censores de imprenta. ${ }^{24}$

\section{Análisis de las fuentes para el estudio de las publicaciones no periódicas editadas en Estados Unidos sobre temas cubanos}

En ciertas ciudades norteamericanas, a donde emigró un mayor número de cubanos, comenzaron a imprimirse una serie de libros, folletos y cuadernos sobre temas relacionados con la Isla, en español y en inglés, que son la mejor muestra del interés y el apoyo prestado a la causa independentista cubana. Del análisis de esas publicaciones se puede detectar de forma evidente el posicionamiento y la corriente ideológica que de ellas se desprendía.

22 AHN, Ultramar, 2097, exp. 21. Gaceta de La Habana. Ley de Imprenta para la Isla de Cuba de 1881. Título XIII. Art. 91. La Habana, 1881.

23 BNJM, Colección Manuscritos. Memorias de la Sociedad Económica de Amigos del País. La Habana, 1895. t. 2, pág. 82.

24 ANC, Gobierno General. Multas a impresores, 171, exp. 8880. La Habana, 1879. De este y otros temas da fe la importancia y "dedicación" que nos muestra ingente (impresionante) documentación que se conserva en el Archivo en donde son más de tres mil los expedientes relacionados con censores y tribunal de imprenta. 
La cobertura del análisis que aquí presentamos se ciñe, principalmente, a las publicaciones no periódicas que de una u otra forma llegaron a Cuba tras ser editadas en Estados Unidos. No nos referimos a la prensa, o publicaciones similares, de aparición periódica, ya que nos limitamos a tratar la información que por el soporte elegido tenía un carácter más duradero y un contexto diferente. Por ello, aquí analizaremos monografías, cuadernos $^{25} \mathrm{y}$ folletos. ${ }^{26}$

Así, hemos tomado como fuentes las publicaciones de dos bibliotecas cubanas. Primero, las que hoy se conservan en la biblioteca de la Oficina del Historiador de la Ciudad de La Habana, la más selecta en cuanto a temas cubanos, situada en el antiguo Palacio de los Capitanes Generales. ${ }^{27}$ Por otro lado, los fondos adquiridos en 1895 por la Biblioteca de la Sociedad Económica de Amigos del País de La Habana.

De la primera biblioteca se han seleccionado todas las obras que fueron publicadas en Estados Unidos, que pudieron llegar a la Isla de forma legal o ilegal, y que a pesar de no dejar constancia de en qué momento llegaron, nos ofrecen una información inestimable sobre qué se publicaba en esos momentos en el país vecino. De ellas se ha realizado un análisis de su contenido y otro del soporte que lo contiene. Sin embargo, este tipo de información necesitaba contrastarse con otra, ya que no se han encontrado los libros de registro de adquisiciones de las bibliotecas que la precedieron. Una información de este tipo era esencial para saber en cada momento de la historia de Cuba cuál era la temática de las publicaciones estadounidenses que se adquirían en esa época de forma oficial. Es decir, conocer qué publicaciones entraban en una biblioteca pública controlada todavía por la metrópoli, o lo que es lo mismo, qué información era la permitida por el gobierno español en esos momentos. Por desgracia, los libros de registro de las bibliotecas no abundan en archivos y bibliotecas públicas ni cubanas, ni españolas. Como siempre existen excepciones, y una de ellas es el registro de adquisiciones de la Biblioteca de la Sociedad Económica de Amigos del

25 Cuaderno: "Conjunto de cuatro pliegos metidos uno dentro del otro, donde se escribían noticias, las ordenanzas o instrucciones". Martínez de Sousa, J.: Diccionario de Bibliología y Ciencias Afines. Madrid, 1989, pág. 188.

26 Según Martínez de Sousa "folleto" es un "impreso no periódico que consta de más de cuatro páginas y de menos de cincuenta. Sobre todo son utilizados en los impresos propagandísticos".

27 Formada principalmente por los fondos de la Biblioteca Histórica Cubana y Americana "Francisco González del Valle". Biblioteca inaugurada en 1938 que a su vez es el resultado de la suma de varias colecciones privadas de importantes representantes de la cultura de esa época: Emilio Roig de Leuchsenring —su director-, Enrique Gay-Calbó, Francisco G. del Valle, Fermín Peraza, Joaquín Llaverias, Emeterio S. Santovenia y un largo etc. 
País, en un año tan significativo como el de 1895. De esta manera podemos obtener, como si de una foto se tratara, una instantánea de la vida de esta institución en uno de sus aspectos fundamentales: la adquisición de obras. La fecha ha sido seleccionada por dos motivos principales: uno, porque las Memorias de la Sociedad Económica, de ese año nos suministran un estudio estadístico muy completo, desde el punto de vista bibliográfico externo, y, por otro lado, porque es el comienzo, el 24 febrero, del alzamiento definitivo en armas con el llamado "Grito de Baire". ${ }^{28}$

\section{Publicaciones editadas en Estados Unidos en las colecciones privadas cubanas}

Realizado el primer trabajo de selección entre las publicaciones de la segunda mitad del siglo XIX que se conservan en la Biblioteca de la Oficina del Historiador, ${ }^{29}$ el fondo documental resultante se compone de 123 obras que fueron publicadas en Estados Unidos. Estas suponen el 22\% del total en esos años.

La mayoría de estos libros y folletos son de carácter político y podrían encuadrarse en tres grupos principales: el reformista encabezado por José Antonio Saco, el autonomista de Rafael Montoro, y el separatista de Joaquín Infante. Pero la publicación de obras cubanas en el país vecino no es una característica de fines de siglo, sino que tuvo sus antecedentes en los años cuarenta. Desde esta década existe una corriente anexionista organizada que se instala en Nueva York sobre el "Consejo Cubano", integrado por Gaspar Betancourt Cisneros, Cristóbal Madam y Miguel Teurbe. El instrumento activo de esa corriente fue el general español, nacido en Venezuela, Narciso López. ${ }^{30}$ De los libros quizás una de las obras más representativas sea Ideas sobre la incorporación de Cuba a los Estados Unidos de Saco, respondida incluso desde la misma ciudad, Nueva York, en una serie de folletos sin editorial, en los que pocas veces aparece el nombre de los autores y la ciudad en la que se publicaron. Con algunas excep-

28 López Civeira, F.: "Estados Unidos y la Guerra de Independencia de Cuba". En: Loyola Vega, O. (Coor.): Cuba: la revolución de 1895 y el fin del imperio colonial español. México, 1995, pág. 153.

29 La documentación seleccionada y analizada procede de los fondos Raros y Valiosos y Colección Bibliográfica Cubana de la Biblioteca de la Oficina de Historiador de la Ciudad de La Habana.

30 Portell Vila, H.: Narciso López y su época. La Habana, 1930-58, 3 t. 
ciones, es muy significativo que una gran mayoría de estas obras ${ }^{31}$ careciera de autor y lugar de edición, aunque supuestamente - como así manifiesta la historiografía cubana actual — fueron impresas en Estados Unidos. La repuesta a posteriores obras de Saco tiene iguales características, ${ }^{32}$ aunque parte de los autores ya se deciden a firmar sus obras. ${ }^{33}$

El lugar de edición de la mayoría de las publicaciones analizadas se corresponde con las ciudades que mayor número de cubanos emigrados recibieron: Nueva York, Filadelfia, Boston y varias poblaciones de la Florida, y que eran además los centros impresores más importantes del país.

Martí, durante su estancia en los Estados Unidos, describió esta situación, que sirve de primera explicación a las cifras que encontramos en la tabla 1: “... los libros que por centenas (salen) cada día, en tal abundancia que no hay conocimiento humano que no esté en ellos ya especializado y diluido, brotan de las imprentas nunca desocupadas de Boston, Nueva York y Filadelfia; que en Chicago imprimen poco".34

\section{TABLA 1}

\begin{tabular}{ccr} 
Ciudades de impresión & Totales & Porcentajes \\
\hline Nueva York & 91 & $74 \%$ \\
Filadelfia & 11 & $9 \%$ \\
Boston & 4 & $3,3 \%$ \\
Key West & 4 & $3,3 \%$ \\
Washington & 3 & $2,4 \%$ \\
Chicago & 2 & $1,16 \%$ \\
Otros & 8 & $6,84 \%$
\end{tabular}

31 Algunos ejemplos son: Ideas sobre la incorporación de Cuba en los Estados Unidos, en contraposición á las que ha publicado don José Antonio Saco, escrito por Betancourt se supone que en Nueva York, 1849. 28 págs.; y la Contestación a un folleto titulado: Ideas sobre la incorporación de Cuba en los Estados Unidos por don José Antonio Saco, de Manuel Quibús, son 23 págs. que supuestamente se publicaron en Nueva York en 1849. En ninguno de estos folletos aparece mencionado el autor en la portada.

32 La Verdad; dos palabras al Sor. Saco, Nueva York, 1851, 12 págs. anónimas; o Cartas de Pero Grullo, supuestamente publicada en la misma ciudad un año después, que consta de 16 págs. también anónimas; o la Oración fúnebre, 10 págs. publicadas ese mismo año que aunque no consta su autor se atribuye a Narciso López, quien lo depositó en la entrada de la biblioteca de la Universidad de La Habana en señal de protesta frente al gobierno colonial.

33 Dos obras que se supone se publicaron en Nueva York en 1852 son la de Orihuela, A.A. de: Dos palabras sobre el folleto La situación política de Cuba y su remedio, publicado en París por D. José Antonio Saco en octubre de 1851, que consta de tan sólo 8 páginas, y la de Villaverde, C.: El señor Saco con respecto a la revolución de Cuba, de 21 págs.

34 Martí Perez: Obras completas... pág. 420. 
Existe otra característica que diferencia la producción de las imprentas norteamericanas sobre temas cubanos. Nueva York no sólo supone las tres cuartas partes de esta producción sino que, probablemente debido a la emigración cubana y a su organización, se convierte en el centro de publicaciones en idioma español de temas cubanos en el exilio.

Filadelfia es la segunda ciudad más importante, sin embargo, la producción era casi siempre en idioma inglés. El español se utilizó preferentemente para temas históricos, biografías, discursos y literatura, cuyas obras serían publicadas por una imprenta que destacará sobre las demás: "Levytype". El inglés era utilizado para publicar los incidentes y luchas del pueblo cubano en su búsqueda de la independencia.

Otras ciudades como Boston o Washington dedican sus esfuerzos a publicar en inglés temas bélicos en los que se trata al pueblo cubano como la víctima de la situación colonial, y los Estados Unidos aparecen como "observador neutral" que apadrina la causa cubana. El resto de las impresiones encontradas definen un panorama poco organizado, disperso y más sujeto a las necesidades del momento que a planes de actuación a medio o a largo plazo.

La excepción es Key West, en Florida, donde imprentas de significativos nombres como "El Obrero", "Revista Popular" y "La Propaganda" publican en castellano ensayos, biografías y folletos en apoyo de la causa, como La revolución cubana y la raza de color de Manuel de la Cruz Fernández (1895), o La guerra de Cuba de L. Portillo (1896). Esta originalidad respecto al resto de las ciudades se debe a la cercanía geográfica de la Isla y a la masiva emigración cubana a Florida, ${ }^{35}$ en la que destaca el gran número de trabajadores del ramo del tabaco.

Un posterior análisis de las obras publicadas en inglés vuelve a ofrecer la primacía a Nueva York, con un $47 \%$ del total frente a un $9 \%$ de Boston, otro tanto de Washington y un 6\% de Filadelfia. También es destacable el hecho de que en un $13 \%$ de los formatos encontramos un escueto "US" en el lugar de impresión.

Un tercer análisis de las publicaciones según fecha de edición (Tabla 2), deja evidencia del aumento discontinuo registrado conforme avanza el siglo. Siendo las décadas del 50, 70 y sobre todo 90 en las que se registran mayor número de publicaciones. Períodos en donde podemos observar de forma más clara las inquietudes socio-políticas y en los que se desarrollan los conflictos más importantes entre la metrópoli y la Isla. Vamos a analizarlo más detenidamente.

35 Alvarez Quijano, J.: Historia de La Florida. Florida, 1932. pág. 363 y ss. 
Las obras encontradas en esta biblioteca previas a 1850 corresponden a trabajos publicados en la ciudad de Filadelfia en 1839, que ya ofrecen en castellano temas literarios cubanos de autores como la condesa de Merlín, ${ }^{36}$ y políticos como el Juicio de residencia... del capitán general Tacón, ${ }^{37}$ contestado desde Nueva York por Salustiano de Olózaga ${ }^{38}$ en ese mismo año.

Por su relevancia es destacable la voluminosa obra de Jacobo de la Pezuela Ensayo histórico de la Isla de Cuba, un clásico publicado en Nueva York en 1842, y la no menos conocida y replicada de José Antonio Saco a la que aludíamos anteriormente, o las Notes on Cuba de J. Wurdemann, publicadas en Boston en 1844.

\begin{tabular}{|c|c|c|c|c|c|c|}
\hline \multirow{3}{*}{$A \tilde{N} O S$} & \multirow{3}{*}{ LIBROS } & \multicolumn{3}{|c|}{ TABLA 2} & \multirow{3}{*}{ TOTAL } & \multirow{3}{*}{$\%$} \\
\hline & & \multicolumn{3}{|c|}{ FOLLETOS } & & \\
\hline & & Total & Con editorial & Sin editorial & & \\
\hline $1840-49$ & 3 & 3 & 1 & 2 & 6 & $5 \%$ \\
\hline $1850-59$ & 6 & 16 & 5 & 11 & 22 & $18 \%$ \\
\hline $1860-69$ & 5 & 1 & 0 & 1 & 6 & $5 \%$ \\
\hline $1870-79$ & 10 & 13 & 4 & 3 & 23 & $19 \%$ \\
\hline $1880-89$ & 6 & 0 & 0 & 0 & 6 & $5 \%$ \\
\hline 1890-98 & 46 & 14 & 11 & 3 & 60 & $48 \%$ \\
\hline TOTALES & 76 & 47 & 21 & 26 & 123 & $100 \%$ \\
\hline
\end{tabular}

Pero será a partir de los años cincuenta, con el desarrollo de los hechos socio-políticos y la cada vez más abundante emigración hacia Estados Unidos, cuando las imprentas allá radicadas se pongan en marcha al mismo ritmo de los acontecimientos. Así en 1850, Cristóbal Madam, uno de los fundadores del Consejo Cubano, escribiría y publicaría en Nueva York su pensamiento en un libro de más de 250 páginas en inglés, titulado

36 Merlin, Mercedes Santa Cruz, condesa de.: Historia de la Hermana Santa Inés. Filadelfia, Impr. de J.C. Clark, 1839, 260 págs.

37 Olañeta, J.A. de: Juicio de residencia del escelentísimo (sic) señor don Miguel Tacón, ó sea colección de escritos presentados por su apoderado y defensor. Filadelfia, Impr. de A. Walker, 1839. 201 págs.

38 Olozaga, Salustiano de: Espresión(sic) de agravios, presentado por el procurador del Ayuntamiento de La Habana, ante el Supremo Tribunal de Justicia, en los autos promovidos sobre cargos en residencia al ex-gobernador y capitán general de la isla de Cuba don Miguel Tacón. New York, Impr. de Lesuein, 1839, 51 págs. 
Cuba, and the Cubans; comprising a history of the island of Cuba, y Saco continuaría publicando sus obras, a las que seguirían sus respectivas réplicas. También encontramos varios libros y folletos sobre temas cubanos de actualidad o históricos en Nueva York y Boston. En estos años es destacable la producción de folletos de la imprenta neoyorquina "La Verdad", sin autor conocido, con menos de 15 páginas y con títulos tan sugerentes como: De la ciencia política, Catecismo político, etc.

Ya en la década de los setenta, la imprenta y librería de Néstor Ponce de León, ${ }^{39}$ situada en Nueva York, asumirá hasta final de siglo las funciones propias de un pequeño centro editor. Por ello, publica en 1875 en dos tomos una de las mejores ediciones de las Obras Poéticas de José María Heredia, la novela de Suárez Romero titulada Francisco, y el Diccionario biográfico cubano de Francisco Calcagno, una de las obras más representativas de la bibliografía cubana del siglo XIX. Otras imprentas menos conocidas publicaban libros de Ferrer Couto, como la de "Esteban Hallet" que sacó a la luz una de sus obras en la que se ofrecían cinco razones para restablecer el tráfico ilícito de esclavos,$^{40}$ la imprenta de "El Cronista" que publicaba títulos como Cuba puede ser independiente (1872), o La verdad (1876) del mismo autor, al que Moreno Fraginals califica de especialista en Institutional advertising negrera. ${ }^{41} \mathrm{La}$ de "E.H. Jones" cuestionaba la situación social en Cuba publicando un folleto de Enrique Dónderis, ${ }^{42}$ la "de Zarzamendi" edita en 1871 la obra de E. Piñeyro Morales Lemus y la Revolución de Cuba; estudio histórico; o aquellas cuyo significativo nombre hablaba por sí solo de sus intenciones: la imprenta de "La Revolución" ofrecía en 1869 las obras políticas del conocido profesor y divulgador de importantes trabajos sobre agricultura Francisco Javier Balmaseda, como Los confinados a Fernando Poo e impresiones de un viaje a Guinea.

En los años ochenta se evidencia un fuerte estancamiento editorial. En el último año de este período Trujillo emprende en su taller el más ambicioso proyecto editorial realizado por un impresor cubano en todo el siglo: el Álbum de "El Porvenir", cinco tomos de gran formato - con 25 semblanzas biográficas cada uno, gran cantidad de ilustraciones y un total de 620 páginas- que se publicaron en Nueva York entre 1890 y 1895. En

39 Alvarez Conde, J.: Néstor Ponce de León. La Habana, 1952.

40 Ferrer de Couto, J.: Los negros en sus diversos estados y condiciones; tales como son, como se supone que son, y como deben ser. Nueva York, 1864, 310 págs.

41 Moreno Fraginals: El ingenio... tomo I, pág. 295.

42 Donderis, E.: La cuestión de Cuba. Nueva York, 1876, 43 págs. 
Filadelfia, Cabrera y Bosch ofrece a la imprenta "Levytype" la 7. a edición de su libro, prologado por el autonomista Rafael Montoro, Cuba y sus jueces; rectificaciones oportunas, y de ese taller salen también un año después las memorias de los tiempos de estudiante del mismo autor. Mientras, en Key West Manuel de la Cruz saca a la luz las biografías de tres ilustres cubanos: ${ }^{43}$ José Antonio Cortina Sotolongo, Enrique Varona y Manuel Sanguily. Se publican además algunos libros de viajes y novelas de autores cubanos y norteamericanos. En este período también aparecen folletos como la conferencia que José Martí leyó a su llegada a Nueva York en 1880: Asuntos cubanos.

En la última década asistimos al desarrollo de un movimiento editorial fuerte cuando la confluencia de varios elementos básicos (editores capaces, en un mercado propicio y una organización que hace posible una relación dinámica entre ambos) confluyan con la creación del Partido Revolucionario Cubano en 1892. De tal forma, que esa masa relativamente dispersa y desorganizada políticamente bajo raras excepciones, encuentra al fin el medio de articular y encauzar sus esfuerzos. En estos momentos, los editores separatistas son los propios impresores y los más importantes defensores de esta causa. En esta relación son nombres importantes José Dolores Poyo, decano del gremio; Enrique Trujillo, director y propietario de la imprenta "El Porvenir", de Nueva York; y Sotero Figueroa, propietario de la imprenta "América" de la misma ciudad. ${ }^{44}$ Otras imprentas de dueños estadounidenses, como las de "G.P. Putnam", "Thompson y Moreau", "W. Johnson", "R.H. Ruseell", "Street \& Smith", "J.B. Chandler", "J.L. Little" "J. Munroe", etc., se unen a esta carrera, aunque de forma mucho menos profusa.

La eclosión editorial se desarrolla en un clima de exaltado patriotismo, debates virulentos y crecientes expectativas de independencia. ${ }^{45} \mathrm{Se}$ publican una serie de libros y folletos cuyos títulos son suficientemente expresivos, los autores firman sus obras, y tan sólo encontramos una pequeña cantidad de folletos editados en la ciudad de Nueva York en los que no aparece la imprenta o el editor. Los años 1892 hasta 1895 marcan este inicio, entrando en la guerra dialéctica autores de renombre como

43 Cruz Fernández, M.: Tres caracteres; bocetos biográficos cubanos. Key West (Flo.), 1889, 69 págs.

44 Fornet, A.: El libro en Cuba. La Habana, 1994, pág. 178.

45 Sobre folletos políticos en la segunda mitad del siglo XIX véase: Vitier, M.: "Las ideas en Cuba”. Trópico, Habana, 1938, t. I, cap. VI, págs. 199-225. 
Quesada Aróstegui, ${ }^{46}$ colaborador de Martí, publicando obras en las Imprentas "América" y "El Porvenir".

Sin embargo, la gran producción editorial tiene lugar a partir del año 1895, alcanzando su culmen en el año del fin de la guerra. Este fenómeno no es específico de los Estados Unidos, sino que afecta a otras grandes capitales de América Latina y de Europa, en las que se publican libros sobre Cuba. Pero lógicamente la producción neoyorquina es la que marca la pauta, ya que de los 47 títulos publicados en Estados Unidos, 33 son de Nueva York. En esta época también crecen de forma considerable las obras en inglés, ya que suponen el $36 \%$ del total.

Los folletos aumentan igualmente su número y las imprentas neoyorquinas se centran en ellos; los temas son de polémica y denuncia, y toma fuerza la literatura de campaña. Aquellas obras que no tienen entre sus páginas la editorial o imprenta, publican casi exclusivamente temas de denuncia; son los folletos de Sanguily como Cuba y la furia española (1895) o José Martí y la revolución cubana (1896), de F.G. Piera Spanish misrule in America (1897). La imprenta "América" sigue la misma tónica general, publicando en 1896 los folletos de Sanguily La anarquía española y el sacrificio de los cubanos, del novelista Armas y Céspedes La perfidia española ante la revolución cubana, del bayamés Izaguirre Asuntos cubanos; colección de artículos y poesías, del médico Borrero Echevarría En la intimidad; a Diego Vicente Tejera o de Eduardo Yero La voz de Caín; cartas abiertas a Rafael Montoro. Mientras tanto, la imprenta "El Porvenir" continúa en su esfuerzo de publicar en formato libro, y ofrece en 1896 los apuntes históricos de Trujillo, su propietario, que recoge los movimientos revolucionarios de cubanos en Estados Unidos en el último quinquenio. ${ }^{47}$

Los años 1897 y 1898 registran también un considerable aumento editor, los folletos son denuncias de situaciones del momento bélico por el que atraviesa la Isla, mientras que los libros se convierten en denuncias razonadas y en planteamientos de futuro sobre la situación en Cuba. En formato libro, Barroeta publica, sin editor conocido, Los sucesos de Cienfuegos y la situación actual de la Isla de Cuba en 1897, y la imprenta de "Howes"

46 Quesada Aróstegui, Gonzalo de: Mi primera ofrenda. New York, Impr. "El Porvenir", 1892, 149 págs. Patriotismo, cuentos de guerra. New York, Impr. "América”, 1893, 212 págs.; e Ignacio Mora. New York, 1894, 184 págs.

47 Trujillo, E.: Apuntes históricos; propaganda y movimientos revolucionarios cubanos en los Estados Unidos desde enero de 1880 hasta febrero de 1895. Nueva York, Impr. "El Porvenir", 1896, 227 págs. 
publica un libro anónimo titulado Por la independencia. Al año siguiente, casi todas las monografías encontradas son revisiones históricas realizadas por autores de todas las partes implicadas en la guerra: cubanos como Quesada y Merchán publican Free Cuba; her opression and Struggles for liberty, history and description of the Island; españoles como L.O. Diviñó, Pro-patria; exposición al Excmo. Sr. Don José Canalejas, delegado del gobierno español para informar acerca del problema cubano, y autores norteamericanos que escriben sobre el pasado, presente y futuro de Cuba como F.M. Noa (The pearl of Antilles; a view of the past and glance at the future), Hall (Cuba, it's past, present and future), de la imprenta "Street \& Smith", y R.H. Davis (Cuba in war time).

Estos dos años se caracterizan sobre todo por la aparición de folletos de todas las razones políticas de unos y de otros. La imprenta "América" edita El dualismo autonomista del literato Nicolás Heredia, El fracaso colonial de España de Varona, y la imprenta de "A.W Howes" saca a la luz una buena muestra de la literatura de campaña: La Victoria de las Tunas de Sanguily. En el mismo sentido, también algunas imprentas neoyorquinas publican correspondencia de guerra, como las de F.R. Woodward, o las del futuro presidente Tomás Estrada. El resto de las imprentas de las otras ciudades se ven menos afectadas por esta avalancha de folletos, y responden con obras terminadas de literatura y demostraciones históricas.

Las ediciones del último año del siglo no pertenecen al movimiento editorial de la emigración, ya que coinciden con la ocupación estadounidense de Cuba tras la guerra con España. Una vez apagado el fuego independentista, el círculo neoyorquino deja de producir masivamente, y durante ese año encontramos, casi exclusivamente, obras publicadas sobre la pasada guerra con una evidente carga partidista, como las 766 páginas de J.R. Young sin editorial conocida, Reminiscences and thrilling stories of the war by returned heroes, las notas del conflicto hispano-norteamericano del Departamento de Guerra estadounidense, o The Rough Riders, de Theodore Roosevelt en Nueva York, explicando el intervencionismo, apoyándose en las figuras del cowboy y el marine. Mientras en Washington se sigue la misma línea, y aparecen autores como Charles Morris (The war with Spain; a complete history of the war of 1898 between the United States and Spain), publicado por J. B. Lippincott en 1899), que ofrecen explicaciones al pueblo sobre la importancia de las nuevas posesiones adquiridas, en sendas obras de más de 500 páginas. En Filadelfia, T. White publica Our new possesions; a graphic account, descriptive and historical, of the tropics islands 
of the sea which have fallen under our sway, de justificación similar a la de Morris, poco después del fin de la guerra; biografías e historiografía heroicas, The rescue of Cuba; an episode in the growth of free government, de B. Silver; y análisis de autores norteamericanos como Mahan, el ideólogo del intervencionismo, sobre la actitud española, bajo el título Lessons of the war with Spain and other articles, publicada en Boston, o la situación creada en Cuba tras el final de la guerra con España: Under three flags in Cuba; a personal account of the Cuban insurrection and SpanishAmerican War, de G.C. Musgrave.

\section{La presencia editorial norteamericana en una biblioteca cubana en 1895}

Uno de los "clientes" naturales de cualquier obra impresa suelen ser las bibliotecas, y las imprentas norteamericanas también surtían de publicaciones "autorizadas" a estas instituciones públicas cubanas. Para estudiar este tema nos basaremos en las adquisiciones de una de estas instituciones, concretamente las realizadas durante el año 1895 por la Biblioteca de la Sociedad Económica de Amigos del País de La Habana, una de las más representativas de su género en todo el siglo XIX ${ }^{48}$ que contó en ese año con más de 4.500 visitantes según consta en las Memorias. ${ }^{49}$

Las 5516 obras adquiridas, clasificadas según el tipo de formato, como ya hicimos con el anterior análisis de la otra biblioteca, aparecen en la tabla 3. Es una cifra considerable si la comparamos con las que ingresan el año anterior, 2117. Es un dato representativo que en esta época tan convulsiva, aumentaran las adquisiciones un $261 \%$ en tan sólo un año.

TABLA 3

\begin{tabular}{cccccc} 
AÑO & Vols. & Folletos & Cuadernos & Periódicos & Láminas \\
\hline 1895 & 924 & 622 & 3882 & 84 & 4
\end{tabular}

48 Sánchez Baena: "Bosquejo histórico de las principales bibliotecas habaneras durante el siglo XIX”. Baluarte. Universidad de Cádiz, 1997. (En prensa).

49 BNJM. Memorias de la Sociedad... Habana, 1895, 3 t. 
La nota más llamativa, a primera vista, en la tabla 3 es que los cuadernos representan la mayoría de las publicaciones, con un $78 \%$ del total, siendo los volúmenes y folletos el $14 \%$ y el $8 \%$ respectivamente.

Con el análisis del origen de las publicaciones obtenemos el lugar de procedencia, tanto el país como la ciudad donde se llevó a cabo la impresión de cada una de las obras.

\begin{tabular}{lcc}
\multicolumn{3}{c}{ TABLA 4} \\
& NÚMERO DE PUBLICACIONES & \\
\multicolumn{1}{c}{ PAÍSES } & Totales & $\%$ \\
\hline Cuba & 2519 & $48 \%$ \\
Estados Unidos & 1233 & $23 \%$ \\
Francia & 777 & $15 \%$ \\
España & 553 & $11 \%$
\end{tabular}

De las cifras de la tabla 4 se desprenden algunos resultados significativos. Como parece lógico, la Isla ${ }^{50}$ ocupaba el primer puesto en el número de impresiones, casi la mitad de éstas. En segundo lugar aparecen, y es el tema que nos ocupa, con un $23 \%$, los Estados Unidos. Este dato es relevante porque las publicaciones procedentes de este país duplican en cantidad las llegadas desde la metrópoli. No sólo la cuestión geográfica, sino sobre todo la política desarrollada por aquéllos va a ser determinante tanto en el contenido como en la edición material de las publicaciones, inundando el mercado editorial con obras de pequeño y mediano formato, mucho más ágiles y menos costosas. En un tercer lugar se sitúa Francia, con un $15 \%$, superando, también, a la todavía metrópoli, que con un $11 \%$ demuestra que era incapaz de surtir a la Isla de las publicaciones que ésta demandaba. ${ }^{51}$

Sin embargo, la cantidad global de publicaciones puede inducirnos a error si no tenemos en cuenta, como ya dijimos, el formato de éstas. Para ello hemos elaborado la tabla 5.

50 Aunque es evidente que en esos momentos Cuba no era todavía un país independiente, hemos considerado oportuno incluirla así para facilitar la lectura y el tratamiento de los datos.

51 Sánchez Baena: "Análisis externo de las adquisiciones de la biblioteca de la Sociedad Económica de Amigos del País de La Habana en los inicios de la guerra de independencia". $V$ Encuentro de Latinoamericanistas Españoles. Sevilla, 1995. (En prensa). 
JUAN JOSÉ SÁNCHEZ BAENA

TABLA 5

\begin{tabular}{lcccr}
\multirow{2}{*}{ PAÍSES } & (total) & \multicolumn{3}{c}{ Publicaciones según FORMATO } \\
\cline { 3 - 5 } & & Vols. & Folletos & Cuadernos \\
\hline Cuba & $(2519)$ & $53(2 \%)$ & $376(15 \%)$ & $2090(83 \%)$ \\
USA & $(1233)$ & $52(4 \%)$ & $43(3 \%)$ & $1138(92 \%)$ \\
Francia & $(777)$ & $553(71 \%)$ & $69(9 \%)$ & $155(20 \%)$ \\
España & $(553)$ & $196(35 \%)$ & $86(16 \%)$ & $271(49 \%)$
\end{tabular}

El mayor número de volúmenes corresponde a Francia, seguido de España, Cuba y Estados Unidos. En lo referente a folletos y cuadernos, Cuba es la que cuenta con mayor producción. Esto nos indica varias cosas: que a nivel científico, las publicaciones "clásicas" seguían llegando del continente europeo, y de la mano de Francia, como hasta entonces se había venido haciendo. ${ }^{53}$ El elevado número de folletos, y sobre todo cuadernos cubanos, nos indica el grado de desarrollo de las imprentas cubanas, o lo que es lo mismo: a) que no era una industria fuerte como para editar libros o volúmenes de gran número de páginas, (aunque si lo fuera para sacar a la luz publicaciones periódicas, menos costosas y con alguna esperanza de amortización o continuidad) y b) que el desarrollo editorial cubano era todavía insuficiente para competir con Europa, y sobre todo con Estados Unidos. Sin embargo, no debemos entender que la Isla no contara con suficiente infraestructura, ya que existían en ese momento sólo en La Habana más de 50 imprentas, ${ }^{54}$ sino que la producción estaba realmente encorsetada por la mano de la censura, y ocupada, sobre todo, en ofrecer las publicaciones oficiales.

La tabla 5 también indica que la biblioteca apuesta por adquirir, sobre todo, obras de pequeño formato en cuanto al número de páginas se refiere. Son publicaciones menos costosas y suelen ofrecer información mucho más actualizada. Con este criterio, es Estados Unidos quien suministraba de forma oficial el mayor número de cuadernos, tras la propia empresa editorial cubana. Sin embargo, observamos diferente tendencia en cuanto a los porcentajes de los formatos adquiridos de Francia y España con respecto a

\footnotetext{
cada país.

52 Los porcentajes al lado de la cantidad son los correspondientes a cada tipo de formato en

53 Sánchez Baena: "Análisis externo de las...”.

54 Sánchez Baena: El libro en Cuba: ..., pág. 171 y ss.
} 
las monografías. Parece claro que la censura no dejaba introducir desde Estados Unidos a Cuba más obra impresa que la de temática no comprometida, como literatura ${ }^{55}$ (sobre todo novelas) y revistas de actualidad que comenzaban en esa época, y que precisamente por ello se eligiera como soporte más adecuado el cuaderno.

Si nos adentramos en analizar las ciudades cuyas obras llegaron a la biblioteca, obtenemos una localización geográfica concreta que puede ayudarnos a corroborar ideas anteriores. En la tabla 6, se detallan las cinco ciudades con un número más significativo de impresiones:

TABLA 6

\begin{tabular}{lrcc}
\multicolumn{1}{c}{ CIUDADES } & Vols. & Folletos & Cuadernos \\
\hline La Habana 2446 & 45 & 352 & 2049 \\
Nueva York 780 & 20 & 28 & 732 \\
París 740 & 525 & 68 & 147 \\
Madrid 427 & 166 & 71 & 193 \\
Washington 383 & 14 & 5 & 383
\end{tabular}

Debemos resaltar un primer dato significativo. Las cifras por ciudades nos evidencian que, en Cuba, casi todo se resumía a la capital, ya que de las 2519 publicaciones editadas en la Isla, el $96 \%$ corresponden a la ciudad de La Habana, siendo el centro impresor y editor por excelencia. En cambio, sólo en Estados Unidos existía una demanda suficiente como para no estar delimitada a una sola ciudad. De esta forma, Nueva York (16\%) y Washington ( $8 \%$ ) cubren esa "necesidad" de publicaciones. También hay que apuntar que aquí estamos analizando tan sólo las adquisiciones permitidas oficialmente, y que podían estar en una biblioteca pública. A estas deberíamos unir las introducidas "ilegalmente", que formaban parte del despliegue propagandístico y de ideología separatista o anexionista que llegaban a la Isla.

El siguiente criterio, el idioma (tabla 7), nos ofrece otra variable significativa: en el formato cuadernos, el español supone el 66\%, en tanto que al inglés le corresponde ya el $30 \%$. Si bien en el análisis de la biblioteca anterior no era extraño que en Estados Unidos los talleres de cubanos emi-

55 Gaur, A.: A history of writing. New York, 1984. 
grados publicaran en inglés, sí que llama la atención que en una biblioteca pública cubana se adquiera un número considerable de cuadernos en inglés. Este hecho puede deberse a la necesidad de adquirir revistas ${ }^{56} \mathrm{y}$ obras publicadas en Estados Unidos frente a las que la censura no actuaba de forma tan rápida. ${ }^{57}$ Además, en esta época el inglés no era un idioma desconocido en la isla, ya que desde las primeras décadas del siglo XIX, y fruto de la intensa relación comercial con el vecino del norte, se comienzan a imprimir en la Isla publicaciones periódicas cubanas en español e inglés. ${ }^{58}$

\section{TABLA 7}

\begin{tabular}{lcccc} 
IDIOMAS & (total) & Vols. & Folletos & Cuadernos \\
\hline Castellano & $(3418)$ & $39 \%$ & $83 \%$ & $66 \%$ \\
Inglés & $(1248)$ & $7 \%$ & $9 \%$ & $30 \%$ \\
Francés & $(673)$ & $54 \%$ & $8 \%$ & $4 \%$
\end{tabular}

Otro parámetro importante a tener en cuenta es el año en que fueron impresas las publicaciones adquiridas en 1895. Del análisis se observa cómo el mayor número de obras comienzan a partir de las décadas de los ochenta y noventa, fechas que coinciden con un aumento de la producción editorial dentro y fuera de la Isla. El número de imprentas no sólo había aumentado, sino que éstas se habían modernizado, y la situación social y política muchas veces era propicia. Las cifras de 1890-95 — 2740 cuader-

56 En estos momentos en Estados Unidos, debido a la rebaja de las tarifas postales en 1879, comenzó a tener un auge espectacular la venta de revistas como Cosmopolitan, Minsey's, McClure's, Scribner's, Ladie's Home Journal y Saturday Evening Post. Eran más económicas que algunos diarios, contenían asuntos públicos, literatura y artes, y acabaron popularizando un tipo de historias cortas.

57 El artículo 91 de la Ley de imprenta para la isla de Cuba de 1881 (y posteriores como la de 1886) trata de las impresiones que llegan a Cuba desde el extranjero y dice textualmente: "Se exceptúan de esta disposición los libros impresos en idioma extranjero, cuya introducción y circulación no podrán prohibirse gubernativamente hasta que se haya incoado contra ellos querella o denuncia criminal ... entendiéndose que la responsabilidad respecto a los libros impresos en el Extranjero recaerá sobre los que verifiquen su expedición o circulación en el territorio de la Isla”. AHN, Ultramar, 2097, exp. 21. Ley de Imprenta para la Isla de Cuba de 1881. Gaceta de La Habana (Miércoles, 4 de mayo de 1881).

58 Ejemplos los tenemos en las décadas de 1820 y 1850 con varios periódicos bilingües de temática comercial, como es el caso del Diario Mercantil de La Habana, que desde 1823 tenía un suplemento semanal en inglés titulado The Mercantile Weekly Report, editado durante varios años y sustituido posteriormente por hojas sueltas en edición bilingüe. Sánchez Baena: El libro en Cuba: ..., págs. 153 y 154 . 
nos, 49 folletos y 57 volúmenes - son demostrativas de esa eclosión de la imprenta cubana, ya que respecto al período 1880-89 se duplica el número de cuadernos y aumenta en casi un $50 \%$ el resto de los formatos en tan sólo cinco años. Cruzando esta variable con las ciudades (tabla 6) podemos corroborar que la gran mayoría de los cuadernos estaban impresos en La Habana y Nueva York.

La temática de esas obras también aporta un dato importante al estudio del fondo: la literatura ocupa el primer puesto, 56\% (las novelas por entregas en cuadernos suponen una buena parte de estas cifras), seguidas de la materia médica y sanitaria (13\%), artes, industria y comercio (11\%) e historia (6\%). El posterior análisis de las consultas revela que las obras más solicitadas coinciden con los temas más adquiridos (con la excepción de las obras de referencia), lo que corrobora que las adquisiciones se correspondían con las demandas de los casi cinco mil usuarios que visitaron ese año la biblioteca.

\section{Conclusiones}

La censura editorial ejercida en Cuba ahogó durante siglos la producción de las imprentas de la Isla. En el interior, la demanda de publicaciones no pudo ser satisfecha ni con la producción propia ni con la de la metrópoli. A partir de la segunda mitad del siglo XIX Estados Unidos se había convertido en el centro suministrador de maquinaria, de formación especializada y de nuevas ideas, que ya no llegaban desde el otro lado del Atlántico. A la dependencia económica, — no debemos olvidar que en el año 1895 la Isla exportaba casi el $86 \%$ de su producción azucarera al vecino país- vinieron a unirse otras.

Para Estados Unidos, Cuba era un mercado interesante por dos motivos: el primero, porque era un mercado editorial que estaba en franca consolidación y expansión, y el segundo, porque se presentaba como contexto idóneo para el cumplimiento del cada vez más cercano "destino manifiesto". La emigración cubana a Estados Unidos aprovechó el gran desarrollo de las imprentas norteamericanas para sumarse a la batalla ideológica contra el poder colonial español. El ritmo de crecimiento de la producción en estas imprentas fue paralelo al desarrollo y organización de los grupos revolucionarios en el exilio norteamericano, y respondía con frecuencia al desarrollo de los acontecimientos bélicos que tenían lugar en Cuba. 
Las imprentas no sólo sirvieron para dar salida a las espectaculares publicaciones periódicas, sino que la batalla librada tomó también forma en otro tipo de publicaciones muy concretas: el folleto y el cuaderno, campos de expresión de ideas, económicos y ágiles. Y convirtió a Nueva York en el centro político e impresor por antonomasia del exilio cubano.

El panorama editorial norteamericano, una vez acabada la confrontación hispano-norteamericana, varía la línea ideológica y de acción, dedicando sus esfuerzos a publicar en formatos de gran tamaño (dejando atrás la propaganda en folletos) razones, causas y motivos, escritos y editados por autores estadounidenses, sobre el dominio de la Isla y del resto de las nuevas posesiones. 